\section{Health outcomes approach}

Continued from page 103

principles for prevention and care, developing prevention programs and models of care based on these principles, identifying infrastructure and training needs, and building these changes into policy and service configuration.

The development of principles depends on published evidence or, if published evidence is not available, a consensus of expert opinion. The principles form a basis for guidelines, policies or protocols designed to improve services, access to services and health status. Consultation with stakeholders is an essential component.

Prevention programs and models of care can be developed based on these principles and the guidelines, policies or protocols, and partners identified to collaborate in the process.

Infrastructural and training issues need to be addressed if effective service models and programs are to be implemented. These include resource allocation, local, state or federal policy, service configuration and links to other sectors. Systems to monitor quality of care and prevention, based on defined indicators and incorporating processes for review, are essential.

In addition, requirements for intersectoral links to address issues outside the health sector should be assessed.

Question 7: How much will it cost?

An integral component of the processes outlined under Questions 5 and 6 is the need to identify the resource implications of the changes. It is placed under a separate question to highlight its importance.

To ensure the best use of resources, the cost-effectiveness of interventions at an Area and District level and at a statewide level must be assessed in conjunction with a determination of available resources. This should be used to inform resource allocation. While in the longer term proposed changes may reduce the cost of the health service, in the shorter term additional resources may be required to effect changes.

\section{Question 8: How well did it work?}

An evaluation plan must be developed and the prevention programs and models of care evaluated using the agreed process and outcome indicators. Based on the evaluation, recommendations may be made to improve prevention and care. The evaluation process should determine the appropriateness, effectiveness, efficiency of the service, satisfaction of consumers with the service and the resultant health outcomes.

Question 9: How do we generalise and sustain it? Finally, there is a need to arrive at methods for institutionalising changes in service arrangements by developing and sustaining the networks for prevention and care. This may be achieved by wider implementation of the changes or by developing mechanisms to ensure their continued support. This may involve incorporating aspects of the changes into business plans and using the systems already developed to ensure ongoing monitoring of quality and outcomes.

\title{
WAITING LIST REDUCTION PROGRAM: INITIAL RESULTS
}

Nick Shiraev and Jean McGarry

System Planning \& Performance Branch

Policy \& Planning Division

NSW Health Department

\begin{abstract}
The May 1995 issue of the NSW Public Health Bulletin contained an introductory article on some concepts and definitions relating to waiting lists in NSW public hospitals ${ }^{1}$, encompassing both medical and surgical elective admissions. This article examines the impact of the NSW Government's Waiting List Reduction Program for elective surgery from its inception in May 1995 until the end of September 1995.
\end{abstract}

The aim of the program is to reduce the March 31, 1995 elective surgery waiting lists by 50 per cent within 12 months, concentrating on people who have been waiting more than six months for surgery.

A key element of the program is to improve hospital practices through the introduction of best practice models. These include better operating theatre scheduling, planned bed management and streamlined admission and discharge practices to ensure more efficient and effective management and better patient care.

Some Area and District Health Services are implementing initiatives such as pre-admission clinics and day-of-surgery admissions, weekend and after-hours surgery, extension of existing theatre sessions and more effective utilisation of existing theatre time.

Waiting list data must be accurate to be a useful management tool. One means of achieving this is through what is known as clerical auditing. This integral part of waiting list management has been Health Department policy for some years. Regular and routine auditing of lists ensures that good quality information is available to managers and administrators and facilitates better patient communication and care. Patients waiting longer than six months are contacted every three months to ascertain whether they still require admission. This enables them to discuss options with the hospital and at the same time provides up-to-date information for theatre scheduling, discharge planning and bed management.

\section{DEFINITIONS}

\section{Elective surgery}

Elective surgery is surgery which, although deemed necessary by the treating clinician, can be delayed, in the clinician's opinion, for at least 24 hours.

NSW has adopted the nationally agreed definition of elective surgery, as specified by the Australian Institute of Health and Welfare. This essentially includes all surgical operations from the Medicare Benefits Schedule ${ }^{2}$ except for certain procedures ${ }^{3}$. The exclusions cover specific procedures frequently done by clinicians without special qualifications in surgery, and some other procedures for which the waiting time is strongly influenced by factors other than the supply of services.

\section{Waiting times}

The expected waiting time (or "clearance time") is the time required to clear the waiting list for specified 
categories of patients. It is equal to the number of patients on the list divided by the number removed from the list in one month. For example, a hospital has a list of 100 patients waiting for total hip replacements. The hospital carries out 25 hip replacement operations a month, so it has an expected waiting time of four months for hip replacements.

The average waiting time is the average of the actual waiting times (the time between the date of listing and the date of admission) for those patients admitted in the month. For example, if half the patients admitted in July had been waiting for one month and half had been waiting for three months, the average waiting time for July would be two months.

The average time on list is the average of the actual waiting time (the time between the date of listing and the end of the current month) for those patients still on the list at the end of the current month.

\section{List transfers}

List transfers occur when lists previously held only in doctors' rooms or interstate are transferred to hospitals and are added to the hospitals' lists.

A list transfer is expressed as the number of patients added to a hospital's list.

List transfers were first measured several years ago as a means of refining measures of growth in demand as indicated by the length of lists. Because list transfers are an administrative change and do not reflect a change in local demand, they are not taken into account for the purposes of comparison with earlier lists. However, when a new list is started with the appointment of a new doctor, the increase is included in the count for comparative purposes, because it represents a genuine increase in demand.

\section{RESULTS}

By September 30,1995, the elective surgery waiting list had decreased from 44,707 to 34,299 patients (a 23 per cent reduction).

Twenty-nine Areas and Districts had a decrease in lists, one had no change, two reported a negligible increase and two still showed an increase (Table 2).

The best-performing Areas were Western Sydney (43 per cent reduction, representing a decrease of 2,012 patients), South-Eastern Sydney ( 28 per cent reduction - 1,985 patients) and South West Sydney (25 per cent reduction 1,134 patients). Among the Districts with the larger lists in March 1995, major decreases were reported by MacleayHastings (a 37 per cent reduction, or 144 patients), North West (34 per cent reduction - 412), New England (28 per cent reduction - 113) and Richmond (26 per cent reduction 180) (Table 2).
In March 1995, 2,265 people had been on the waiting list more than 12 months and 6,379 had been on the waiting list for 6-12 months. By 30 September 1995 these figures had declined by 837 ( 37 per cent) and 2,617 (41 per cent) respectively. The reduction by 3,500 patients waiting more than six months has been a significant effect of the program, indicating that Areas and Districts were targeting longer-waiting patients (Table 3).

Western and South Eastern Sydney Area Health Services reported large reductions in the numbers of people waiting more than twelve months - 204 (69 per cent) and 301 (54 per cent) respectively. In Northern Sydney and Western Sydney Areas the number of patients waiting 6-12 months declined by three-quarters and almost two-thirds respectively, while South Eastern Sydney Area Health Service reported a decrease of 524 patients (a 46 per cent reduction) in this group (Table 3 ).

Riverina and Macleay-Hastings District Health Services reported that the numbers of people waiting more than 12 months decreased by 66 ( 86 per cent) and 35 ( 76 per cent) respectively (Table 3), while the New England District had no patients waiting more than six months at the end of September.

As a consequence of the initial concentration on patients who had been waiting for the longest time, the average waiting time of patients who were admitted in a month increased from 1.4 months in March to 1.6 months in September 1995.

Decreases in list numbers were recorded over all clinical specialties. Particularly significant were reductions in numbers of people waiting longer than six months for procedures such as cholecystectomy (down by 162 patients 55 per cent), cataract extraction ( $501-41$ per cent), tonsillectomy ( $310-50$ per cent), varicose vein stripping and ligation (151 - 36 per cent) and total hip replacement (56-31 per cent).

\section{COMMENT}

Reductions occurred in the length of waiting lists for elective surgery between March and September 1995. Future issues of the Public Health Bulletin will contain updates on waiting lists and future analysis will include waiting times. The possibility of exploring relationships between waiting times and morbidity is also being considered.

1. Shiraev N, McGarry J, Frommer M. Waiting lists in NSW public hospitals. NSW Public Health Bulletin, 1995, 6(5): 37-39.

2. Commonwealth Department of Health, Housing, Local Government and Community Services. Medicare Benefits Schedule Book Operating from 1 November 1998. Australian Government Publishing Service, Canberra.

3. National Health Data Committee. National Health Data Dictionary Version 4.0. Canberra: Australian Institute of Health and Welfare, 1995, p3-3. 


\section{TABLE 2}

REDUCTIONS IN WAITING LISTS BY AREA AND DISTRICT HEALTH SERVICE, MARCH TO SEPTEMBER, 1995

\begin{tabular}{|c|c|c|c|c|}
\hline \multirow[b]{2}{*}{ Area/District/Institution } & \multicolumn{2}{|c|}{ Number of patients on list } & \multicolumn{2}{|c|}{$\begin{array}{c}\text { Total } \\
\text { reduction } \\
\text { March to September }\end{array}$} \\
\hline & March 31, 1995 & September 30, 1995* & $\begin{array}{l}\text { March } \\
\text { Number }\end{array}$ & $\%$ \\
\hline $\begin{array}{l}\text { Central Sydney } \\
\text { Northern Sydney } \\
\text { Western Sydney } \\
\text { Wentworth } \\
\text { South West Sydney } \\
\text { Central Coast } \\
\text { Hunter } \\
\text { Illawarra } \\
\text { South Eastern Sydney } \\
\text { Royal Alexandra Hospital } \\
\text { Barwon } \\
\text { Castlereagh } \\
\text { Central Western } \\
\text { Clarence } \\
\text { Evans } \\
\text { Far West } \\
\text { Hume } \\
\text { Lachlan } \\
\text { Lower North Coast } \\
\text { Macleay-Hastings } \\
\text { Macquarie } \\
\text { Mid North Coast } \\
\text { Monaro } \\
\text { Murray } \\
\text { Murrumbidgee } \\
\text { New England } \\
\text { North West } \\
\text { Orana } \\
\text { Richmond } \\
\text { Riverina } \\
\text { South Coast } \\
\text { Southern Tablelands } \\
\text { Tweed Valley } \\
\text { Port Macquarie Base Hospital }\end{array}$ & $\begin{array}{r}2,779 \\
2,708 \\
4,650 \\
2,122 \\
4,514 \\
2,317 \\
4,178 \\
2,778 \\
7,190 \\
792 \\
43 \\
51 \\
588 \\
199 \\
330 \\
204 \\
413 \\
111 \\
1,071 \\
385 \\
813 \\
887 \\
59 \\
16 \\
- \\
404 \\
1,213 \\
33 \\
681 \\
1,276 \\
89 \\
187 \\
824 \\
802 \\
\end{array}$ & $\begin{array}{r}2,259 \\
2,034 \\
2,638 \\
1,654 \\
3,380 \\
1,906 \\
3,583 \\
2,321 \\
5,205 \\
592 \\
34 \\
40 \\
705 \\
11 \\
244 \\
148 \\
310 \\
83 \\
835 \\
241 \\
690 \\
686 \\
69 \\
18 \\
- \\
291 \\
801 \\
32 \\
501 \\
1,044 \\
43 \\
180 \\
636 \\
1,085\end{array}$ & $\begin{array}{r}-520 \\
-674 \\
-2,012 \\
-468 \\
-1,134 \\
-411 \\
-595 \\
-457 \\
-1,985 \\
-200 \\
-9 \\
-11 \\
117 \\
-188 \\
-86 \\
-56 \\
-103 \\
-28 \\
-236 \\
-144 \\
-123 \\
-201 \\
10 \\
2 \\
- \\
-113 \\
-412 \\
-1 \\
-180 \\
-232 \\
-46 \\
-7 \\
-188 \\
283\end{array}$ & $\begin{array}{r}-18.7 \\
-24.9 \\
-43.3 \\
-22.1 \\
-25.1 \\
-17.7 \\
-14.2 \\
-16.5 \\
-27.6 \\
-25.3 \\
-20.9 \\
-21.6 \\
19.9 \\
-94.5 \\
-26.1 \\
-27.5 \\
-24.9 \\
-25.2 \\
-22.0 \\
-37.4 \\
-15.1 \\
-22.7 \\
16.9 \\
12.5 \\
-28.0 \\
-34.0 \\
-3.0 \\
-26.4 \\
-18.2 \\
-51.7 \\
-3.7 \\
-22.8 \\
35.3\end{array}$ \\
\hline New South Wales & 44,707 & 34,299 & $-10,408$ & -23.3 \\
\hline
\end{tabular}

Source: Department of Health Reporting System, October 12, 1995

- Excludes transfers - List transters, in general, are an administrative change and not a change in local demand.

They are therefore not taken into account when estimating changes in the number of patients on a list (see definitions). 


\begin{tabular}{|c|c|c|c|c|c|c|c|c|}
\hline \multirow[b]{4}{*}{ Area/District/Institution } & \multicolumn{8}{|c|}{ NUMBER ON LIST } \\
\hline & \multicolumn{4}{|c|}{ Waiting 6-12 months } & \multicolumn{4}{|c|}{ Waiting > 12 months } \\
\hline & \multicolumn{4}{|c|}{ Reduction } & \multicolumn{4}{|c|}{ Reduction } \\
\hline & Mar 31, 1995 & Sept 30, 1995 & Number & $\%$ & Mar 31, 1995 & Sep 30, 1995 & Number & $\%$ \\
\hline $\begin{array}{l}\text { Central Sydney } \\
\text { Northern Sydney } \\
\text { Western Sydney } \\
\text { Wentworth } \\
\text { South West Sydney } \\
\text { Central Coast } \\
\text { Hunter } \\
\text { Illawarra } \\
\text { South Eastern Sydney } \\
\text { Royal Alexandra Hospital } \\
\text { Barwon } \\
\text { Castlereagh } \\
\text { Central Western } \\
\text { Clarence } \\
\text { Evans } \\
\text { Far West } \\
\text { Hume } \\
\text { Lachlan } \\
\text { Lower North Coast } \\
\text { Macleay-Hastings } \\
\text { Macquarie } \\
\text { Mid North Coast } \\
\text { Monaro } \\
\text { Murray } \\
\text { Murrumbidgee } \\
\text { New England } \\
\text { North West } \\
\text { Orana } \\
\text { Richmond } \\
\text { Riverina } \\
\text { South Coast } \\
\text { Southern Tablelands } \\
\text { Tweed Valley } \\
\text { Port Macquarie Base Hosp }\end{array}$ & $\begin{array}{r}116 \\
404 \\
836 \\
340 \\
555 \\
398 \\
768 \\
463 \\
1,150 \\
25 \\
- \\
- \\
80 \\
1 \\
2 \\
1 \\
25 \\
13 \\
207 \\
101 \\
164 \\
150 \\
- \\
- \\
- \\
26 \\
169 \\
4 \\
95 \\
199 \\
4 \\
1 \\
79 \\
3\end{array}$ & $\begin{array}{r}71 \\
156 \\
207 \\
192 \\
415 \\
303 \\
430 \\
279 \\
626 \\
4 \\
- \\
1 \\
96 \\
- \\
2 \\
- \\
22 \\
- \\
203 \\
31 \\
82 \\
73 \\
- \\
- \\
- \\
- \\
81 \\
1 \\
32 \\
113 \\
1 \\
2 \\
300 \\
\end{array}$ & $\begin{array}{r}-45 \\
-248 \\
-629 \\
-148 \\
-140 \\
-95 \\
-338 \\
-184 \\
-524 \\
-21 \\
- \\
1 \\
16 \\
-1 \\
- \\
-1 \\
-3 \\
-13 \\
-4 \\
-70 \\
-82 \\
-77 \\
- \\
- \\
- \\
-26 \\
-88 \\
-3 \\
-63 \\
-86 \\
-3 \\
1 \\
-40 \\
297\end{array}$ & $\begin{array}{r}-39 \\
-61 \\
-75 \\
-44 \\
-25 \\
-24 \\
-44 \\
-40 \\
-46 \\
-84 \\
- \\
- \\
20 \\
-100 \\
- \\
-100 \\
-12 \\
-100 \\
-2 \\
-69 \\
-50 \\
-51 \\
- \\
- \\
- \\
-100 \\
-52 \\
-75 \\
-66 \\
-43 \\
-75 \\
100 \\
-51 \\
9,900\end{array}$ & $\begin{array}{r}15 \\
173 \\
295 \\
293 \\
191 \\
107 \\
179 \\
173 \\
559 \\
11 \\
- \\
- \\
8 \\
- \\
- \\
- \\
4 \\
- \\
52 \\
46 \\
41 \\
4 \\
- \\
- \\
- \\
1 \\
16 \\
1 \\
77 \\
- \\
- \\
19 \\
-\end{array}$ & $\begin{array}{r}8 \\
213 \\
91 \\
184 \\
198 \\
81 \\
131 \\
149 \\
258 \\
- \\
- \\
- \\
12 \\
- \\
- \\
- \\
- \\
- \\
30 \\
11 \\
41 \\
2 \\
- \\
- \\
- \\
3 \\
2 \\
3 \\
11 \\
- \\
- \\
-\end{array}$ & $\begin{array}{r}-7 \\
40 \\
-204 \\
-109 \\
7 \\
-26 \\
-48 \\
-24 \\
-301 \\
-11 \\
- \\
- \\
4 \\
- \\
- \\
- \\
-4 \\
- \\
-22 \\
-35 \\
- \\
-2 \\
- \\
- \\
- \\
-1 \\
-13 \\
2 \\
2 \\
-66 \\
- \\
- \\
-19 \\
-\end{array}$ & $\begin{array}{r}-47 \\
23 \\
-69 \\
-37 \\
4 \\
-24 \\
-27 \\
-14 \\
-54 \\
-100 \\
- \\
- \\
50 \\
- \\
- \\
-100 \\
- \\
-42 \\
-76 \\
- \\
-50 \\
- \\
- \\
-100 \\
-81 \\
- \\
200 \\
-86 \\
-100 \\
- \\
-\end{array}$ \\
\hline New South Wales & 6,379 & 3,762 & $-2,617$ & -41 & 2,265 & 1,428 & -837 & -37 \\
\hline
\end{tabular}

Source: Department of Health Heporting System, October 12, 1995

\section{PUBLIC HEALTH EDITORIAL STAFF}

The editor of the Public Health Bulletin is Dr Michael Frommer, Director, Research and Development, NSW Health Department. Dr Lynne Madden is production manager.

The Bulletin aims to provide its readers with population health data and information to motivate effective public health action. Articles, news and comments should be 1,000 words or less in length and include a summary of the key points to be made in the first paragraph. References should be set out using the Vancouver style, the full text of which can be found in British Medical Journal 1988; 296:401-5.

Please submit items in hard copy and on diskette, preferably using WordPerfect, to the editor, NSW Public Health Bulletin, Locked Mail Bag 961, North Sydney 2059. Facsimile (02) 3919029.

Please contact your local Public Health Unit to obtain copies of the NSW Public Health Bulletin. 